\title{
Consumer Specialization and the Demand for Novelty: a Reconsideration of the Links and Implications for Studying Fashion Cycles in Tourism
}

\author{
Andreas Chai* \\ Griffith Business School, Griffith University
}

JEL D03; D12; L83

Novelty demand; consumer specialization; habituation; tourism patterns.

\begin{abstract}
Summary
How does the consumer's predisposition to seek arousing new sensations affect their tendency to accumulate knowledge about consumption activities? Using recent insights about the dynamic interaction of learning mechanisms that are part of the individual's genetic endowment, we argue that, contra Scitovsky (1976), the emergence of relatively convenient forms of entertainment may foster - rather than inhibit - the accumulation of consumer knowledge. Furthermore, because specialized consumers have a greater tendency to innovatively modify aspects of the consumption activity, we argue that this specialization process fundamentally affects the rate at which consumers become habituated to novelty. This represents an important way in which cognitive learning patterns interact with non-cognitive learning dynamics and it has consequences for understanding the direction and length of fashion cycles in recreational activities. In particular, we discuss how this perspective can be applied to studying tourism demand patterns and the 'Destination Life Cycle'.
\end{abstract}

\section{Introduction}

The long run growth of household income since the industrial revolution has led to an immense increase household spending levels and also qualitatively transformed the types good and services that households tend to consume (Lebergott 1993). Through this process an immense variety of new goods and services have entered the consumption basket of ordinary workers (Saviotti 1996). The growing share of household spending dedicated to recreational activities is an important example of this transformation. A wide variety of industries have emerged to supply recreational goods and services related to activities such as tourism, reading books, collecting stamps, and playing online games. Needless to say, technological progress plays an important role in enabling the emergence of new forms of entertainment. Therefore, any appropriate theoretical explanation of what drives the growing variety in entertainment activities needs to account for how new technologies affect the manner in which consumers learn and seek entertainment.

\footnotetext{
* Presented at the 'The Evolution of Consumption' Workshop, 10-12 of December, 2006 at the Max Planck Institute of Economics, Jena, Germany. The author would like to thank Marina Bianchi, Peter Earl, Pier Paolo Saviotti, Christian Schubert, Horst Entorf, Peter Winker, Ulrich Witt and the two anonymous referees for their comments. The usual disclaimer applies.
} 
Here, Tibor Scitovsky devised a highly original theory to account for this phenomena by arguing that with rising levels of affluence, the consumer's want for arousal and search for novelty plays an increasingly important role in motivating consumption activities (Scitovsky 1976; Zuckerman 1994). Not only can this approach explain why spending on recreation increases with rising affluence, but it can also account for why the character of entertainment activities is inherently unstable and subject to continuous change. This occurs because consumers, after prolonged exposure, become less responsive to any one particular stimulus (the habituation effect).

Nevertheless, in his rather overzealous critique of modern consumption culture, we posit that what Scitovsky's theory lacks is a proper account of how consumers accumulate knowledge about, and specialize in, consumption activities. This is problematic because he argues that it is precisely because of the modern consumer's reluctance to accumulate consumption knowledge that a 'Joyless Economy' exists in which more convenient means of attaining arousal that require few skills (e.g. watching television) are preferred over relatively more complex types of entertainment that are a rich source of arousal but require more knowledge and skills from consumers (e.g. watching the opera). Specifically, his critique of modern consumption is based on a depiction of consumer learning that is analogous to firm investment decisions, as featured in household production theory (Becker 1996).

This paper reexamines the link between novelty demand and the consumer specialization process based on more recent insights from cognitive psychology (Anderson 2000) and social psychology (Bandura 1986). According to Witt (2001), consumer specialization is the result of a dynamic interaction of cognitive and non-cognitive learning processes. From this perspective, contra Scitovsky (1976), we reach the conclusion that relatively convenient forms of entertainment can foster -rather than inhibit-consumers to gain detailed knowledge and preferences for particular recreational activities. Furthermore, because specializing consumers have a greater tendency to modify the particularities of the consumption act, we argue that the specialization processes can fundamentally affect the rate at which consumers become habituated to arousing stimuli. We propose that this influence represents an important manner in which cognitive learning processes can affect non-cognitive learning dynamics. We discuss the implications for understanding historical changes in tourism demand patterns, as well as for assessing the effectiveness of investment strategies that aim to halt periods of stagnation in visitors to a tourist destination, as is discussed in the 'Destination Life Cycle' literature.

This paper is structured as follows. Section 2 critically reviews Scitovsky's account of the want for arousal as the chief motivation for the rise of recreational expenditure and discusses how well this explanation is upheld in light of recent advances in neuroscience and social psychology. Section 3 introduces the concept of consumer specialization, examines the conditions that trigger the specialization process, and discusses how it can intervene with the manner in which the habituation process affects entertainment-related consumption activities. Section 4 discusses the implications for understanding the underlying causes of periodic shifts in recreational travel demand. Section 5 concludes. 


\section{Scitovsky on novelty demand and the effects of new technologies}

Entertainment is typically defined as "the act of diverting, amusing, or causing someone's time to pass agreeably" (Vogel 1998). While the average contemporary household contains books, magazines, radios, television, DVD players, computers, and stereo systems, in the early $18^{\text {th }}$ century only around 22 per cent of English households owned books (Weatherill 1988: 26). Today, tourism is a recreational activity that represents a major migratory movement of modern society, involving millions of people ever year, vast sums of money and generating employment around the world (Stabler et al. 2010). The tourism industry is one of the fastest growing sectors of the $20^{\text {th }}$ century (Clancy 1998), which contributes an estimated US\$ 3.3 trillion (11 per cent) to global GDP.

How can one account for this rapid growth in the variety and magnitude of recreational spending? Perhaps it is a simple result of the insatiable nature of the consumer's demand for such activities. Yet this conjecture tends to miss an important point: many recreational activities are continuously subject to periodic and sometimes radical changes which have important welfare implications (Bianchi 2002). Alternatively, Tibor Scitovsky offers a more realistic, behaviorally-grounded account of this phenomenon "The Joyless Economy" (Scitovsky 1976). At the heart of his explanation is the psychological concept of arousal and how humans seek to maintain a particular Intermediate State of Arousal (ISA). ${ }^{1}$ Arousal is defined as the level of alertness or activation of an individual, ranging from extreme drowsiness to extreme wakefulness (Berlyne 1960). Many factors have been identified as influencing the organism's level of arousal. For example, the deprivation of basic wants is a stimulator of arousal, while satiation of hunger tends to reduce arousal (Scitovsky 1976: 29). In general, it has been posited that consumers tend to seek an ISA that is, as Scitovsky put it, being 'between strain and boredom' (Scitovsky 1976: 15; see also Zuckerman 1994: 13; Steenkamp/Burgess 2002; Helm/Landschulze 2009). When the consumer's arousal level is above the ISA, they typically look for ways of reducing arousal (e.g. relaxing after a stressful day, cooling down when too hot). In turn, when the arousal level is too low, consumers look for ways of increasing arousal (e.g. watching television when bored). We dub the former case as the consumer's actual arousal level as the 'want for arousal'.

In order to satisfy this want for arousal, consumers seek exposure to arousing stimuli. The arousal potential is the extent to which a stimulus is capable of raising arousal and generally exciting the nervous system. It is determined by the physical and chemical characteristics of the stimuli (e.g. their loudness, color and temperature). Collative properties (novelty, congruity and complexity) can also positively influence arousal potential (Berlyne 1971). In particular, Scitovsky emphasizes that a very potent source of arousal is novelty (Scitovsky 1976: 31). He notes that when an organism has "eaten, drunk, made love, and is fully satiated and comfortable in all other respects...," one of the few motivations that can stimulate action is a new or unexpected change in the environment (Scitovsky 1976: 33). According to the Wundt curve, stimuli of an intermediate degree of novelty are pleasantly arousing. If the stimuli are too novel, they are perceived as unpleasant (Scitovsky 1976: 35). With rising levels of affluence, Scitovsky argues consumers are less deprived of other basic wants (e.g. food \& suchlike), and hence are more deprived of important sources of arousal: "At an earlier stage of development, the

1 It is originally called the 'optimal state of arousal' but we avoid this term in order to avoid confusion with the economic term 'optimum'. 
ordinary routine of a more difficult existence imposed as much excitement as most people could take, but that progress since then, by reducing the intensity of those unwanted excitements and tensions, has created, for the first time in many people's lives a positive need for excitement, which they seek to fill for enjoyment's sake." (Scitovsky 1981: 5). Therefore, in order to avoid painful boredom, consumers search for ways to increase their arousal level, through either physical or mental stimulation (Scitovsky 1976: 31).

Furthermore, technological progress has also provided more access to novelty in an increasingly convenient fashion. He argues modern forms of entertainment that have emerged with new technologies are more convenient as they require relatively fewer skills from consumers (Scitovsky 1976: 226). For example, to read a book requires consumers to be literate, whilst watching television only requires consumers to look and listen to the television set. Although the latter still requires some skill, the basic level of knowledge the consumers must have to gain some pleasant arousal from the act is relatively lower. Others have come to a similar argument from the perspective that an increasing level of income raises the opportunity cost of time (Lindner 1970; Becker 1996). If one is willing to accept that the accumulation of consumption knowledge is relatively time intensive, then it is not difficult to argue that particularly time-poor consumers tend to pursue types of consumption activities that require less skill on the part of consumers. $^{2}$

Hypothesis 1: Consumers tend to substitute away from high-skill recreational activities towards relatively more convenient recreational activities that require less consumer knowledge.

Scitovsky argues that this preference for more convenient forms of entertainment is problematic as they are relatively poor sources of novelty (Scitovsky 1976: 233). Novelty is a characteristic that is dissipative in that it gets used up in the act of enjoyment through the process of habituation. Because of this process, consumers naturally tend to derive less arousal and become less responsive to a stimulus after prolonged exposure (Scitovsky 1976: 58; Wathieu 2004). As Scitovsky puts it, "what arousal they attain from such 'unskilled' acts as watching television, going shopping and driving is fully adequate when the time devoted to their enjoyment is suitably limited, spaced and selected but quickly becomes redundant, unsurprising, and monotonous as we devote more and more time to them in the vain hope that the intake of novelty will keep step with the increased time we spend on them," (Scitovsky 1976: 233). ${ }^{3}$ This forms the basis for his critique of massproduced goods as their monotonous nature causes consumers to tire of them relatively quickly. Consequently, standardized markets tend to be subject to relatively rapid and periodic changes (Scitovsky 1976: 255). Furthermore, because of their popularity, the individual consumer may be frequently exposed to mass produced goods relatively more often such that the initial arousal they gain from their own purchased good fades much more quickly than was anticipated (Bianchi 2003). ${ }^{4}$

Despite these pitfalls, Scitovsky argues that there would be great demand for standardized goods as modern consumers are generally reluctant to acquire the skill that is

2 For a critique of the 'time-squeeze' argument see (Lebergott 1993: 138).

3 Another critique Scitovsky has of modern consumption relates to the frequency of consumption. Because of their frequency, many consumption acts today do not deliver pleasure (Scitovsky 1976: 71).

4 Scitovsky also has a second critique about the consumption of pleasure, see Bianchi (2003). 
necessary to engage in less convenient forms of entertainment that provided access to richer forms of novelty. This is because, firstly, there is a 'rational bias' against acquiring consumption skills. When deciding to invest in the attainment of skills, the consumer "cannot attach a dollar value to the skill of enjoying a concert or a ballet... With so many unknowns so utterly impossible to estimate, it seems rational... to discount the benefits heavily and to opt instead for adding to our production skill and their easily quantifiable benefits," (Scitovsky 1976: 231).5 Secondly, the nature of modern work increasingly requires a growing number of professional and vocational skills, which tend to 'crowd out' consumption skills and knowledge (Scitovsky 1976: 229). Thirdly, because consumers form habits, they may still continue to use convenient forms of entertainment even when they are no longer arousing (Scitovsky 1976: 124). He argues that consumers derive 'comfort' from the mere act of keeping such old habits. Finally, American culture in particular has a Puritan 'ghost' which is biased against the acquirement of skill purely related to the attainment of pleasure (Scitovsky 1976: 228).

More recently, Zuckerman (2007) extends this theory of novelty-seeking consumption to explain risky behavior such as smoking, drinking, casual sex and taking drugs. Zuckerman distinguishes between two different types of arousal that can be elicited from exposure to novel stimuli. On the one hand there is positive arousal which is a type of pleasure experienced by the consumer. On the other hand, novel stimuli can also elicit negative arousal in the form of anxiety related to the perceived risks involved in undertaking the activity. Zuckerman posits that there exists a link between the novelty of an activity and the perceived risk of the activity "novelty tends to increase risk appraisal, and familiarity tends to reduce it" (Zuckerman 2007: 56), see left panel of Figure 1. This leads to the prediction that, if the stimulus is highly novel, consumers will seek to withdraw from the stimulus in order to achieve ISA as this causes the anxiety experienced to outweigh the positive arousal elicited from the stimulus (region to the Right of $N$ ). On the other hand, for stimulus that is less novel, positive arousal elicited from exposure will outweigh anxiety such that consumers seek to gain more exposure to the stimuli to achieve the ISA (region to the left of $N$ ), an act that he labels 'sensation-seeking'.

This approach suggests that, as consumers are repeatedly exposed to the stimuli, a tendency to take more risks can emerge because of the dissipative nature of novelty. Repeated exposure will lead to a reduction in the anxiety it elicits as consumers become more familiar with the stimulus. On the Right panel of Figure 1, the reduction of novelty elicited by a stimulus is represented by a leftward shift from $E_{1}$ to $E_{2}$ such that the level of anxiety elicited by the stimulus has reduced, but the level of positive arousal experienced by the consumer has remained constant. Given that increased experience reduces the anxiety derived from a risky recreational activity, it is predicted that experienced consumers will seek more stimulating forms of the same activity that previously would have been previously perceived as too novel in their inexperienced state (situated to the right of $N)$.

\subsection{Two criticisms of Scitovsky's approach}

Written in the 1970s, Scitovsky provided one of the first economic discourses on consumption that was informed by neuroscientific insights. Two points of criticisms have since been raised about Scitovsky's theory of growing demand for recreational activities. First, the idea that historically low arousal levels (i. e. greater amounts of boredom) mo-

5 By 'production skill' Scitovsky is referring to skills relevant for employment. 

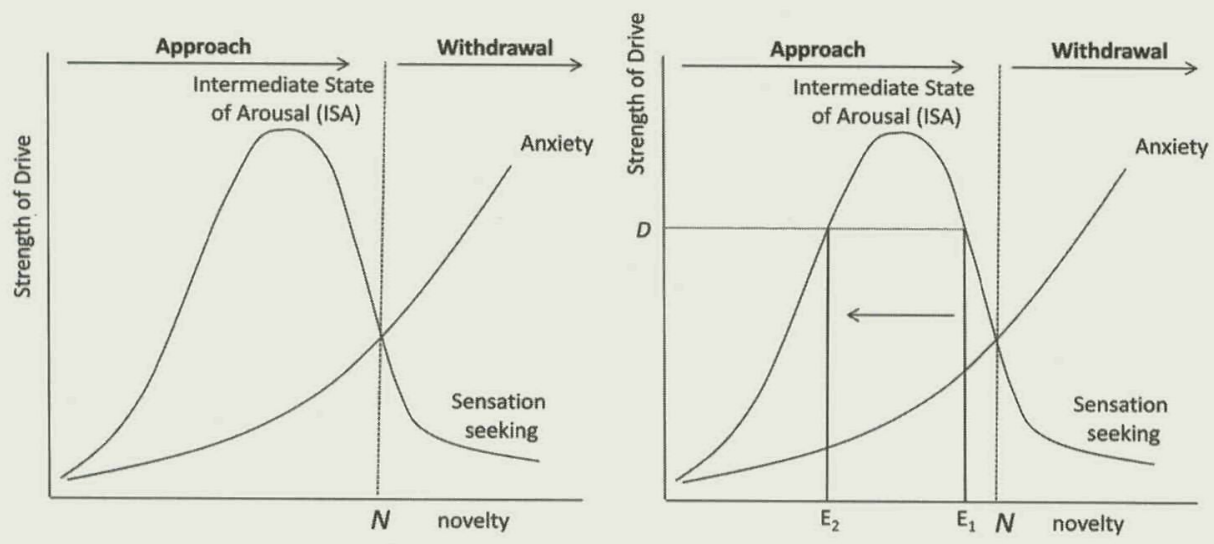

Figure 1 Consumer sensation seeking and Anxiety as a function of the novelty of Stimuli (Left panel source: Zuckerman 2007)

tivate consumers to expose themselves to arousing stimuli has been questioned. To begin with, Scitovsky equates boredom with a state of low arousal (Scitovsky 1976: 31) even though Berlyne, upon whose work Scitovsky builds his argument, sees boredom as related to high arousal (Berlyne 1960:189). Berlyne notes that a low level of arousal is not perceived as unpleasant or distressing, and generally causes subjects in sensory-deprived environments to sleep. It is only when they can no longer sleep that sensory-deprivation is perceived as painful by subjects. While boredom in Berlyne's sense would still be a state which motivates novelty-seeking, it is a very extreme state that would occur rarely, if ever, in day-to-day life (Steenkamp et al. 1996: 321). Earl doubts that modern consumption patterns are driven by boredom since the increasingly complex and diverse nature of goods and services available in affluent societies tends to complicate rather than simplify consumption activities in a way that is increasingly stressful for consumers (Earl 1998: 138).

Secondly, Scitovsky's explanatory framework has no satisfactory conception of how consumers acquire consumption skill. This is important because he argues that it is precisely the declining levels of consumption skills that are responsible for 'joyless' economy. When discussing the consumer's skill acquisition, he views skill as a type of access cost to be incurred in order to access society's past stock of novelty (Scitovsky 1976: 235). This is an implicit analogy to capital investment decisions faced by firms. Such an analogical argument is more famously pursued by Becker (1996), where consumers may accumulate 'personal capital' which can influence the marginal productivity of future consumption activities. As Elster points out, equating consumer learning processes to firm investment decisions is seriously flawed since each investment is assumed to i) be the result of a freely chosen action, ii) lowers utility below what it would otherwise have been, but is nevertheless undertaken because it promises to generate more utility in the future, and iii) is reversible in that it decays unless maintained (Elster 1997: 750). Also such investments are assumed to be undertaken with perfect foresight of their expected consequences.

In Scitovsky's case, the limits to such an analogical approach are clear when we consider the role that knowledge plays in influencing how consumers satisfy their want for arous- 
al. Firstly, unlike firm investment decisions, it is unlikely that there is one unique point in time where consumers decide whether or not to acquire skill. ${ }^{6}$ Rather, skill acquisition seems to be a dynamic process which does not necessarily involve conscious effort (Anderson 2000). In addition, much evidence suggests that through the accumulation of subjective consumption knowledge, consumers have a greater ability to modify aspects of consumption so as to actively discover new dimensions of the consumption activity that can further satisfy the consumers underlying want for arousal. Bianchi states that it is precisely the creative aspect of consumption that is essential to understanding the transformative nature of modern consumption patterns (Bianchi 1998; Bianchi 2002). Through this process, consumers may come to discover new dimensions of the activity through which they may gain exposure to new types of novelty. Hence, unlike firms engaging in investment decisions, the ultimate payoff that consumers gain from learning is shrouded in uncertainty and may vary depending on what they have learn and the extent to which this process leads them to uncover new and arousing features of the stimuli.

\section{An evolutionary approach to consumer specialization}

We proceed to synthesize the theory of novelty-seeking consumption with more recent behavioral accounts of how consumers specialize into certain consumption activities. This serves to deliver a more accurate understanding of how the habituation process may be delayed, or in some cases entirely inhibited, by the consumer specialization process. To do so, it is necessary to adopt a theoretical framework that can take heed of the existence of multiple learning modes and how they may interact.

To this end, we adopt Witt's theory of consumer specialization (Witt 2001). Based on an evolutionary perspective, this approach recognizes that the gradual enlargement of human brain capacity during phylogeny did not evolve in such a way in which there was a smooth substitution of more advanced learning mechanisms for more primitive ones (Flinn 1997: 33; Sartorius 2003). Rather, human brain development was sticky: more advanced mechanisms became effective by complementing older mechanisms. Thus it is important to highlight the different coexisting modes by which consumers learn and how these may interact. This point underlines the chief distinction that needs to be made between 'non-cognitive' and 'cognitive' learning mechanisms. The former corresponds to associationary learning mechanisms that are also possessed by other animals (Skinner 1953). This mechanism is relevant in situations where consumers are 'uninvolved' and 'uncommitted' (Foxall 1990: 14). In such circumstances, consumers do not undertake thoughtful, comparative evaluations of choices. Cognitive learning, on the other hand, refers to the unique human ability to learn by insight (Hergenhahn/Olson 1997). It is the mode of learning where the consumer has dedicated their full mental attention to a particular activity (Anderson 2000).

According to Witt (2001), the consumer specialization process is the result of the dynamic interplay between non-cognitive and cognitive learning processes. On the one hand, via the laws of non-cognitive learning, consumers tend to accumulate a set of likes and dislikes about things and activities that become associated with sources of reinforcement (Skinner 1953). This set of likes and dislike can guide what consumers tend to

6 Similarly, Becker's model assumes that if the future utility yielded by particular investment is less than the cost of the investment, consumer will decide at some point in time not to accumulate personal capital. 
insightfully learn about. At the same time, cognitive learning can influence the set of likes and dislikes consumers possess because new knowledge may lead consumers to change in the details of a consumption act in such a way that would enable new associations to be made between reinforcement and neutral stimuli (Witt 2001: 36). Together, the two effects may be mutually reinforcing and lead to the refinement of both what consumers know and what they like. As such, this theory conjectures that specialized consumer develop both a relatively more specific set of likes and dislikes and a relatively greater knowledge base about a particular consumption activity. For example, wine aficionados do not only know more about drinking wine than the average consumer, they also possess more refined likes and dislikes associated with drinking wine than the average consumers. Through associating certain characteristics of wine with other sources of reinforcement via past experiences (e.g. drinking a wine whilst on an enjoyable holiday), they have acquired likings for a relatively more specific set of wines.

In terms of what triggers specialization, Chai (2011) argues that the likelihood of consumers specializing in a particular recreational activity depends on i) the availability of knowledge about the activity and ii) the extent to which information about the activity is associated with reinforcing stimuli. In relation to i), as specialization involves gathering detailed information about aspects of the consumption act, such a process is fostered by the existence of information sources and knowledge that can inform consumers of these details. In this regard, there is little doubt that the ability to satisfy the want for arousal has strongly benefited from the emergence of a variety of Information, Storage and Communication Technologies (ISCT). These technologies have also fundamentally magnified the unique ability of humans to store and communicate knowledge and information in extra-somatic ways, which forms the basis of cultural evolution (Flinn 1997: 36). Thus many new forms of entertainment simultaneously act as sources of information to the consumer, e.g. watching TV and surfing the web. Hence, via the specialization process, ISCTs have not only affected what type of information consumers possess, but because this information indirectly affect consumption experiences and the formation of likes and dislikes via the specialization processes, they ultimately have also indirectly influenced the type of preferences consumers have accumulated.

In relation to ii), how intensively information about the consumption act is communicated across social networks may also influence what activities consumers tend to specialize in Studies of cognitive learning have established that information which is frequently discussed also tends to be noticed more by individuals (Witt 2001). Witt argues this 'shift' effect helps the human brain screen which incoming messages are attended to. Indeed, social psychologists have found that the presence of peers produces an increase in arousal in the organism (Zajonc 1966). This suggests that the presence of peers could affect what type of arousing stimuli individuals tend to pay attention to as they would start to notice stimuli in the environment which they would previously have ignored. Consequently, groups of intensively communicating individuals can develop similar (dis)likes as well as accumulate knowledge about the same type of consumption activities that are discussed by the group, which can give rise to new consumer sub-cultures (Witt 2001: 36). This social aspect of the specialization process helps explain the synchronized nature of cycles in entertainment-related consumption that are traditionally explained as an outcome of status signaling motives (Chai et al. 2007). In addition, social facilitation research has also shown that the presence of peers affects the cognitive learning process as their presence tends to impair performance on poorly learned or complex tasks, but enhance performance on well-learned or simple tasks (Amabile 1996: 181). Taken to- 
gether, there is much evidence to support the notion that peer relationships and social structures surrounding the individual consumer can have an important influence on the direction and rate of consumer specialization.

\subsection{The economic implications of consumer specialization}

One important outcome of specialization is that consumers have a greater propensity to vary details of the consumption activity. Gaining more detailed knowledge and a more refined set of acquired (dis)likes tends to alter the way consumers assess the performance of goods and services. This can serve to either prolong or shorten the consumer's use of a particular good or service. On the one hand, goods used in the past that were once deemed adequate may at some later stage of the specialization process be regarded as no longer suitable. Consequently, new types of goods and services are demanded that are better suited to the more refined state of the consumer's knowledge and her likings. Examples include high-performance sports cars (Scitovsky 1976: 273) or high-performance cameras (Windrum 2005). In other cases, consumer specialization can lead to greater path-dependence in consumption patterns and the prolonged use of goods and services if consumers have developed specific skills and tastes related to a particular good. One such example is the analogue (shutter-operated) camera, which is still used by many experienced camera enthusiasts, despite the fact that it has been superseded by the digital camera (Moreau et al. 2001).

It is via this tendency to modify aspects of the consumption activity that we hypothesize that certain relatively convenient forms of entertainment may dynamically complement rather than substitute less convenient means of attaining exposure to arousing stimuli. In the context of the want for arousal, specialized consumers will likely seek to vary the manner in which they are exposed to the arousing stimuli about which they have accumulated detailed knowledge. For example, a sports car may come to the attention of a consumer via social communication or through watching a television program. Such arousing stimuli may lead the consumer to buy car magazines, or models of the car, through which they gain more exposure to the stimuli and learn more about cars in general and what particular types of cars they like. Eventually, with rising income, this learning process may lead them to purchase a sports car. Thus one single learning process related to gaining exposure to 'sports car' entails different stages in which there is a significant change in the means used to satisfy the underlying want for arousal.

Hypothesis 2: Via the consumer specialization processes, certain relatively convenient, low-skill recreational activities can dynamically complement (rather than substitute) high-skill, less convenient recreational activities.

This hypothesis could be empirically tested by examining how the level of a consumer specialization affects the consumer's willingness to pay and price elasticity of demand for certain products. The hypothesis implies that specialized consumers would exhibit a relatively higher willingness to pay for recreational goods and services that enable the consumer to flexibly modify the consumption activity to match their particular (dis)likes. Unspecialized consumers should exhibit a lower willingness to pay for such flexibility since their (dis)likes and knowledge are relatively less detailed. This implies they are more likely use standardized goods and services which offer less flexibility but more certainty to the consumer. A start to examining this conjecture was made by Chai (2007) who examined how the specialization process affects the consumer's choice of using 
fully-packaged trips or semi-packaged trips. Fully-packaged trips offer considerable discounts on airfares and accommodation due to realizing economies of scale. In such cases, specialized consumers who prefer more flexibility in their choices face a tradeoff between using those goods that are cheap but do not match their particular likings and using those that are more expensive though they better match the consumer's particular likings. It was found that the consumer's level of specialization was positively correlated with a preference for semi-packaged over fully-packaged trips. This tradeoff has been discussed in the 'General Purpose Technology' literature where the probability that users adopt a common technology depends on the mismatching costs incurred in using a widely available but untailored technology versus using one that is more expensive but tailored to the users' specifications (Bresnahan/Gambardella 1998). As consumer become more specialized, the costs of using unspecialized, mismatched goods and services are not static, but increase in accordance with the nature and speed at which the consumer's knowledge and likings become refined.

\subsection{The effect of consumer specialization on habituation dynamics}

A second implication of consumer specialization is for understanding how the habituation process affects recreational consumption. We argue that this influence takes place in two dimensions: the rate of habituation and the degree to which habituation impacts consumption activities related to the want for arousal. In the literature, habituation is a non-cognitive learning dynamic that most living organisms possess through which a behavioral response to a repeated stimulus wanes after prolonged or repeated exposure to the stimulus (McSweeney/Roll 1998). ${ }^{7}$

Studies have uncovered a number of facts about the habituation process. First, the weaker the stimulus, the more rapid and the more pronounced is habituation (Wathieu 2004: 593). In contrast, very strong stimuli may yield no significant habituation (Thompson/ Spencer 1966: 19). Secondly, the time period between stimuli exposure (interstimuli interval) can affect habituation. Habituation is more rapid and complete when these intervals are short than when they are long. On the other hand, reducing the stimulus rate delays or even inhibits habituation (Wathieu 2004: 592). Thirdly, by exposing an organism to a variety of related stimuli (e.g. the same stimuli presented in different colors and shapes), habituation to one specific stimulus is significantly slowed (McSweeney/ Swindell 1999: 445). In addition, the presentation of extra strong or novel stimuli can also lead to sensitization, which is defined as an increase in the organism's responsiveness to a stimulus (McSweeney/Swindell 1999: 443).

Naturally, there is a substantial difference between the experimental settings in which these studies have taken place and the consumer's everyday environment. Nevertheless insights from habituation processes can be fruitfully employed to study consumption behavior (Wathieu 2004). In particular, this evidence suggests that the specialized consumers' tendency to modify and vary consumption acts could lead to a change in the habituation rate. Modifying consumption activities can change the frequency of exposure, the strength of the stimuli, or the variety of stimuli they are exposed to. For example, in the case of recreational travel, this consumption act can be modified in many potential dimensions, such as what destinations are visited, the speed at which they travel through a particular region, the duration consumers stay in one particular

7 Habituation is thought to be an important mechanism that prevents animals from wasting resources by repeatedly responding to constant stimuli that present little danger or opportunity. 
destination, and the frequency at which consumers are exposed to the same type of attractions.

Some evidence for this influence can be found in the awareness that specialized recreational travelers to the English Lakes District in the $19^{\text {th }}$ century had about how changing the mode of transport would affect the tourist experience. They opposed the construction of a railway in this region as it would diminish the value of being exposed to the arousing stimuli, rendering the act of exposure 'superficial'. William Wordsworth, for example, argued that tourists cannot "gain material benefit from a more speedy access that they now have to this beautiful region..." because "..the perception of what has acquired the name of picturesque and Romantic scenery is so far from being intuitive, that it can be produced only be a slow and gradual process," (Wordsworth 1844). These specialized consumers feared that the blurred nature of the landscape, caused by an accelerated rate of exposure to stimuli, would positively augment traveler's boredom in such a way that tourists would pay more attention to their guidebooks than to the arousing landscapes through which they were passing (Buzard 1993: 36).

We hypothesize that the habituation process is affected by the tendency of specialized consumers to modify aspects of the consumption activity. For example, if consumers alter the speed at which they travel through a particular region, this effects the above-mentioned inter-stimuli interval, which in turn influences the rate at which consumers become habituated to arousing stimuli such as forests or mountains. Furthermore, consumers can vary the strength of exposure by, for example, viewing a landscape first in person rather than viewing it on television or reading a description in a novel. Alternatively, via the above-mentioned variety effects consumers can delay habituation to a particular stimulus by exposing themselves to a variety of stimuli. Sampling a number of different variants of one specific category of arousing stimuli (e.g. forests) thus leads to consumers slowing down habituation to each particular stimulus. Otherwise, by enacting a radical sequential variation of the exposed stimuli, consumers could trigger dishabituation, where the restoration of a response to a habituated stimulus is achieved by the presentation of a strong, or novel, stimulus. For example, after touring various landscapes for a number of consecutive days, exposure to a densely crowded, polluted city may re-sensitize tourists to the beautiful nature of landscapes.

Hypothesis 3: Through their tendency to modify the manner in which they are exposed to arousing stimuli, specialized consumers may delay and/or inhibit the habituation process through changing the strength of the stimulus, the speed of exposure, and the variety of stimuli which they are exposed to.

Using Lancaster's characteristics approach (Lancaster 1966), Hypothesis 3 can be modeled as follows. As shown in Figure 2, consider some class of recreational goods $(G)$ that consists of a bundle characteristics ( $z$ ) featuring: novelty (horizontal axis) and other characteristics (vertical axis). The consumer maximizes their utility by choosing some vector of characteristics $U=U(z)$, subject to $z=B x$, pxk and $z 0$, where $B$ is the consumption technology matrix, $x$ is the vector of goods, $p$ is the vector of prices for goods $x$ and $k$ is income. In Figure 2 the consumer does this initially by choosing some combination of $G_{1}$ and $G_{2}$ represented at point $A$ where their marginal rate of substitution between novelty and other characteristics (represented by IC) is equal to the relative price of $G_{1}$ and $G_{2}$ represented by the tangent $r s$ that is determined by $p$. The effect of habituation is that, over time with increasing exposure after prolonged use, the consumer perceives the good $G_{1}$ to offers relatively less novelty and more of other characteristics $\left(G_{1}^{\prime}\right)$. We assume 


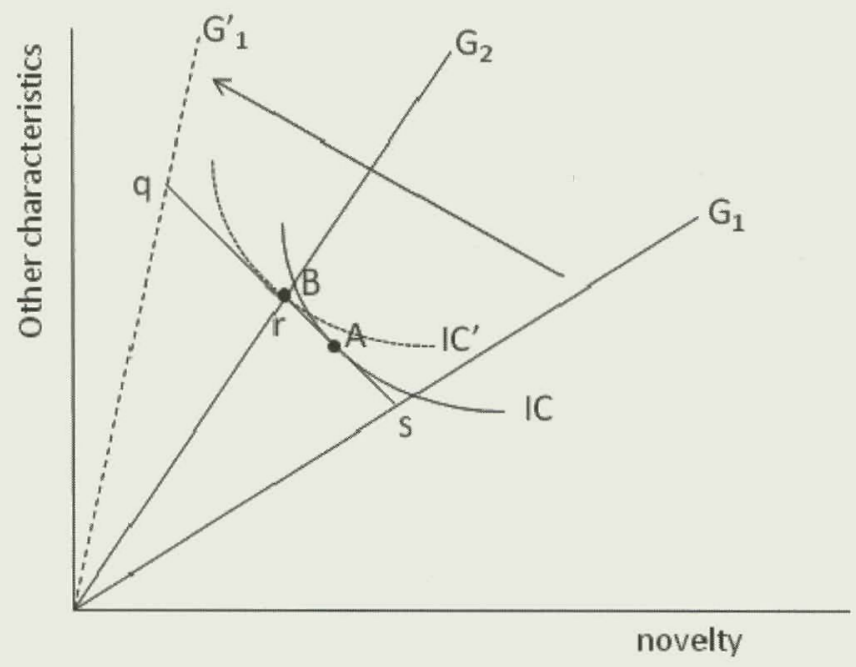

Figure 2 The effect of habituation on the consumption of entertainment goods

that $G_{2}$ is not congruent to $G_{1}$ such that the habituation to $G_{1}$ will not affect the perceived novelty of $G_{2}$. Ceteris paribus and assuming no change in the price of goods, this change in perceptions leads to a change in the combination of goods demanded by the consumer from $A$ to $B$ at which point the consumer is not consuming any of $G^{\prime}{ }_{1}$ and only consuming $G_{2}$, the unhabituated good. Hypothesis 3 says that the degree to which consumers are specialized leads to a slowdown in (or completely inhibits) the shift from $G_{1}$ to $G^{\prime}$. Hence specialized consumers tend to consume $G_{1}$ for a longer period of time relative to unspecialized consumers.

Apart from delaying the habituation process, consumer specialization can also influence how consumers respond to habituation by changing their consumption activities. In particular, the notion of 'stimulus specificity' describes the extent to which habituation to one stimulus does not extend to others. We argue that the accumulation of knowledge can localize the habituation effect in that specialization can change the degree to which consumers classify arousing stimuli. Because of the relatively more detailed knowledge that specialized consumers possess, their habituation patterns occur at a higher level of specificity. For example, after reading a brochure about the sunny Mediterranean, consumers may visit Majorca and consequently become habituated to it. As a result of this habituation, non-specialized consumers may become habituated to the act of traveling to the Mediterranean per se, since they may not know about the differences between Majorca and other destinations in the region. On the other hand, specialized consumers who underwent the same habituation process may also no longer visit Majorca, but nevertheless continue to travel to other places in the region thanks to their relatively more detailed knowledge of that region.

Furthermore, through modifying the details of the consumption act, specialized consumers may also gain exposure to other arousing stimuli that may further motivate consumers to continue engaging in a particular consumption act even after they have become habituated to the original arousing stimuli (Bianchi 2002). For example, by embarking 
on a trip to Majorca, consumers with no previous experience in international travel may develop a liking for local foods, culture, or a particular type of accommodation. This new set of likes and dislikes may trigger consumers to learn more about holidaying in that region in order to gain more exposure to these stimuli. Consequently, even if they become habituated to one particular stimuli that motivated travel (e.g. warm environment), they may still travel to the same destination in order to be exposed to other arousing stimuli which the consumer has discovered at that particular destination. Hence, as a consequence of the discoveryof arousing stimuli, the nature of the consumption act may change significantly and be re-orientated to relatively more arousing sources of stimulation. Thus, specialization may lead consumers to perpetually satisfy their want for arousal by the same act of 'traveling to Majorca', although precisely which arousing stimuli motivates this act may change with habituation. Let us summarize these two arguments about how specialization may mediate the impact of habituation on consumption in the following hypothesis:

Hypothesis 4: Specialization can dampen the impact that habituation has on consumption activities related to the want for arousal because it leads to consumers classifying stimuli in greater detail and can lead consumers to discover new arousing stimuli that become associated with the consumption act.

Together, Hypotheses 3 and 4 provide new theoretical insights into how consumer specialization may affect the manner in which consumers satisfy their want for arousal. From this perspective, Scitovsky's argument that skilled consumption gives access to 'reservoirs of novelty' (Scitovsky 1976: 235) is undoubtedly correct. However it also becomes clear that the accumulation of knowledge does not only influence the quantitative amount of novelty that consumers can enjoy. Rather, Hypothesis 3 argues that specialization also influences the rate at which consumers become habituated to stimuli. Furthermore, Hypothesis 4 suggests that the impact of habituation on such consumption activities can be significantly dampened. In this sense, the process by which consumers acquire consumption knowledge is not just a cost that must be incurred in order to gain access to some given amount of arousing stimuli. Instead, it is transformative in the sense that the discovery of new sources of stimuli may significantly change the source of arousal driving the consumption act.

To conclude, based on how specialization may dampen the effects of habituation, there are two benefits which consumers derive from the specialization process. First, by enhancing the consumer's ability to actively modify the consumption act, specialized consumers gain the extra benefits that accompany 'tailor-fitted' and individualized consumption experiences. However, because specialized consumers also have more refined wants, they may be no better off relative to consumers with little knowledge and unrefined tastes since these refined wants are relatively harder to satisfy. In this regard, as long as the improvement in their ability to modify the details of the consumption act is greater than the degree to which their likings become more refined via specialization, some net improvement from specialization should be realized in terms of the extent to which individuals are able to satisfy their particular wants.

Secondly, concerning the demand for novelty, specialization can deliver potential savings as it reduces the rate at which consumer knowledge becomes obsolete. Because it can delay habituation in such a way that consumers may remain relatively satisfied with the same consumption act for relatively longer periods of time. For example, because of relatively faster habituation rates experienced by unspecialized tourists, they may 
embark on an annual search for new travel destinations. On the other hand, specialized consumers may be relatively satisfied with visiting the same destination for a number of years, as they may delay habituation by varying aspects of their trip, and thus come to associate a destination with newly-discovered arousing stimuli. This enables them to reuse their accumulated knowledge related to the act of traveling to a particular destination, such as learning which hotels provide a satisfactory standard of accommodation in a destination. By increasing the incentive for consumers to revisit the same destination, the usefulness of previously accumulated knowledge is extended through the specialization process. Furthermore, specialization in such a manner also works to diminish the frequency at which consumers face problems that accompany the selection of new destinations to visit. For the very fact that they are novel implies that there is the inherent uncertainty about their potential to satisfy the consumer's set of likes and dislikes. Hence, from this perspective the phenomenon of consumer specialization can be viewed as having a positive impact on the consumers' ability to satisfy their want for arousal.

\section{Application to tourism}

The general notion that knowledge level of individual consumers affects their involvement in recreational activities has been studied in a wide variety of contexts, including bird watching (McFarlane 1994), fishing (Chipman/Helfrich 1988), hunting (Kuentzel/ Heberlein 1992), hiking (Virden/Schreyer 1988) and even polar bear watching (Lemelin et al. 2008). In relation to tourism, many scholars argue that a significant proportion of recreational travel is related to the human's natural tendency to actively explore their environment, related to a longing to learn and experience the unknown (e.g. Stagl 1995: 4). ${ }^{8}$ Compared to other forms of entertainment, long-distance travel takes a relatively long time and there is a high degree of uncertainty pertaining to the hedonic value of the act since it is an experience good. Scitovsky notes that recreational travel is an activity that is rich in arousing stimuli, although there are also many potential inconveniences to endure, for "traveling involves the austerity of summer housing, the discomfort of unfamiliar beds and baths, hazards of restaurant food, crowding, exposure to weather, danger of reservation not being honored (Scitovsky 1976: 194). Studies of tourists have also found that they exhibit a continuum of behavior from 'general interest' to 'very focused involvement', which has an important influence on the type of services demanded (Bryan 2000; Kerstetter et al. 2001). As tourists gain experience, they tend to move along this continuum from low involvement and general recreational interests to high involvement and more specific interests (Bryan 2000). From a historical perspective, recreationaltravel represents a relatively difficult means of attaining exposure to arousing stimuli as it involves a multitude of costs and discomforts. With respect to pre-industrial Europe, Braudel summarizes the history of transport as "bad roads (and) ridiculously low speeds," (Braudel 1992: 42). Even with bearable road conditions, the pre-modern traveler faced a number of other problems, such as expensive toll inspections, changes of routes due to seasonal conditions, and the possibility of attacks by thieves and brigands (Braudel 1992: 52). Furthermore, travel may necessitate the acquirement of skills, such as being able to converse in foreign languages and calculating varying exchange rates between different local currencies.

8 Commonly described as Wanderlust in the tourism literature (Gilbert/Abdullah 2004). 


\subsection{E-tourism and the recreational nature of 'surfing the web'}

Regarding Hypothesis 2, a good example of a recent technology that has spawned new types of recreational activities is the internet. This ISCT has had a profound effect on how consumers communicate with peers, suppliers, find information, manage their finances, or spend their recreational time via 'web surfing' - recreationally browsing the contents available on websites (Beutel et al. 2011). The tourism industry was one of the early pioneers of using web advertising and adopting e-commerce technology. This resulted in more intense price competition because search costs were reduced.

Yet this emphasis on reducing search costs tends to miss the more fundamental point that the internet has also played a role in stimulating demand by exposing consumers to arousing stimuli and information about holidays that motivates them to travel in the first place. Much like a casual visit to the local shopping mall, web-surfing has a dual purpose in that it serves as both an information-search activity and a recreational activity. This dual purpose can explain the seemingly random outcomes of browsing activities: what goods and services the consumers end up buying is unrelated to the initial intentions they possessed when they first commenced the activity (Earl/Potts 2000). Earl and Potts see this type of 'browsing' behavior as an open-ended process through which consumers discover their preferences and the exposure to goods and services has the potential to deliver a realization to the individual that they possess an unsatisfied which they had not been previously aware of. This process is quite different from the standard model of consumer choice, where consumers are assumed to know a priori what their objectives are before they begin searching. The key difference is that consumers draw some intrinsic value from the opportunity to search and uncover different consumption options whilst browsing. This is very similar to the idea in the tourism literature that the tourist experience is to be understood in terms of consuming opportunities to look - the so-called 'tourist gaze' (Urry 1995).

Our approach to novelty-seeking behavior suggests that rather than thinking of consumers using the internet to plan their future recreational activities abroad, it could be useful to think of consumers as beginning their recreational gazing of arousing travel destinations online. In the words of Wilson and Suraya "travel pages on the Internet offer people accessing them possibilities of Luddic escape, both virtual and material" (Wilson/Suraya 2004). This virtual gazing may, via the specialization process, lead to more high-skill manifestation of novelty-seeking wherein consumers physically travel to the arousing stimuli. Web surfing has the potential to foster consumer specialization process for three reasons. Firstly, this activity exposes consumers to arousing stimuli in a number of different formats. In the online context, sensory and hedonic elements such as color, music, action, pictures, graphs, videos, and interactivity are an important aspect of the online consumer experience (Richard et al. 2010). Secondly, web-surfing also offers easily accessible information relating to arousing travel destinations, which allows consumers to conveniently learn more about a travel destination at a relatively early stage at which they are not habituated to the stimuli. In turn, online information may stimulate the consumer to gain repeated exposure to the stimuli by viewing the recreational destination on a number of different source websites. Thirdly, in terms of the shift effect, the internet enables consumers to share and discuss past and potential holiday experiences with peers via social networking sites or travel blogs. Indeed, studies have shown that online travel videos shared by their peers can provide mental pleasure to viewers by stimulating fantasies and daydreams, as well as bringing back past travel memories (Tussyadiah/Fesenmaier 2009). 
Thus by thinking of web surfing as a recreational activity that has the potential to stimulate a specialization process that could lead to consumers embarking on recreational travel, we begin to understand how certain types of consumer demand may be not be "derived" in the sense that it serves some preexisting and latent purpose (Mokhtarian/ Saloman 2001). Rather, demand may be induced by a combination of the want for arousal motivating consumers to seek exposure to novel stimuli and the learning opportunities that they come across during web surfing. In transport economics, the notion of induced demand for travel infrastructure has been used to describe demand which did not exist $a$ priori to the creation of new transport infrastructure, but is stimulated as a result of transport infrastructure improvements (Goodwin 1996). Examples of such induced demand include such undirected travel, such as 'joy-riding' or traveling in an offroad vehicle. Web surfing is similar in nature as it is a result of improvements in ISCTs. It is an open-ended process which enables consumers to be exposed to novel and entertaining stimuli.

The existence of induced demand should not be confused with a Galbraithian view of the power of advertising (Galbraith 1958), given the complex number of factors that may influence the nature of the specialization process (outlined above). Rather, it suggests that the extent to which the open-ended nature of recreational web-surfing leads to actual recreational travel by individual consumers depends on a number of factors: i) the extent to which the consumer possesses an unsatisfied want for arousal; ii) the quality and context in which arousing stimuli related to tourist destinations are presented to the consumer; iii) the availability of information about these arousing stimuli that enables cognitive learning; iv) the capability for consumers to communicate to peers about these stimuli; v) the extent to which the online environment manages to inhibit habituation to stimuli by, for example, ensuring consumer are not repeatedly exposed to the same stimuli in a monotonous fashion.

\subsection{The Destination Life Cycle}

Today, one popular and relatively convenient form of tourism is visiting holiday resorts with the typical 'sun, surf and sand' features. Surveys of resort tourists have repeatedly found that tourists generally consider their stays in such natural environments to be beneficial to their health and general well-being (Inglis 2000; Parrinello 1993). In most historical accounts, the emergence of resort tourism is interpreted as a natural development of the industrial revolution. Its timing is largely attributed to the growing numbers of affluent consumers who considered themselves middle class that constituted a buoyant demand for the seaside in the nineteenth century (Towner 1996: 173). Others emphasize the invention of new forms of mass transport, such as railways, which played a critical role in the invention organized tourism and tourism intermediaries that created a new era of relatively cheap and convenient recreational travel (Urry 1990).

The developmental trajectory of tourist destinations has been intensively studied in the tourism literature (Butler 1980; Agarwal 1997). The 'Destination Life Cycle' is a popular analytical framework used to theorize about certain empirical regularities that have been observed in the growth process and examine the way in which tourist destinations may encounter critical growth thresholds during their development. It charts the stylized development of destinations in terms of a series of stages defined by the change in the number of tourist visitors and infrastructure level (Agarwal 1997). The growth rate of tourists visiting a particular destination typically follows an S-shaped curve, with some saturation limit showing the point where the number of visitors reaches a 
maximum. Once this saturation limit has been reached, destinations reach a critical juncture after which they may either experience a decline, while others enjoy a second growth phase depending on a number of endogenous and exogenous conditions. Over the years since its inception, the limitations of this model have been emphasized both in theoretical critiques and in case studies (Getz 1992; Russell/Faulkner 1998).

A key observation of the Destination Life Cycle literature is that there is an interaction between changing supply conditions and the type of tourists visiting the destination. In the exploration stage only a small number of 'adventurous' tourists visit, but over time, along with the development of infrastructure, a larger number of tourists composed of mainly family-orientated consumers begin to dominate (Butler 1980). This is related to growth of tourism infrastructure that steadily consolidates itself in the form of a growing accommodation capacity, as well as the emergence of tourism-orientated small enterprises and rising public infrastructure (e.g. parks and transport facilities).

In this regard, the theory of novelty-seeking consumers can make an important contribution by accounting for why the growth of infrastructure affects the type of consumers who visit the destination. The growth of capital infrastructure tends to involve a drive towards standardizing good and services. As larger capital investments are realized, there is a natural tendency to impose established standards on the nature of tourism facilities. For example, in order to attain 'star' quality ratings, hotels must possess certain infrastructure characteristics and services (Espinet et al. 2003). In order to achieve returns to scale, large hotels need to attract a wide variety of consumers. To do so, suppliers tend to focus on tastes that are commonly shared in population. As Scitovsky put it, "To render production cheap, the seller must extend his market, he can best do this by catering to desires everybody shares....By catering to these desires the seller fulfills the important economic function of creating the conditions necessary for reaping the economies of scale, cheapening his product, and making that product accessible to all; but at the same he discourages and discriminates against more sophisticated tastes"(Scitovsky 1976: 9). Thus while standardization increases the appeal to a wider number of tourists, it also negatively affects the amount of novelty which destinations may offer to consumers. This in turn renders the destination relatively unattractive to experienced consumers who seek destinations with a high degree of arousal potential. In relation to consumers who seek relatively less novelty, the standardized nature of resorts may increase its appeal to these consumers, but it will also accelerate the rate at which consumer become habituated to such destinations.

A second useful contribution the theory of novelty-seeking consumers can make is in evaluating the effectiveness of strategies to counter slumps in tourist demand. A decline in visitor numbers leads to reductions in profits for local businesses and is typically linked to increased competition from other travel destinations (Agarwal 2002). A common strategy is to undertake new investments that aim to arouse the interest of the mass segment of tourists, such as the constructions of new adventure parks and shopping districts (Priestly/Mundet 1998; Agarwal 2002). These increase the attractiveness of the destination by improving its novelty and reducing the tourists' incentive to search for novel, arousing stimuli elsewhere (Nininen/Riley 2003). As Butler observes,"technology has become a substitute for some, or even all of the [resorts] attributes. The most apparent examples of this are seen in Dubai, Las Vegas and Macao, and perhaps also the Disney theme parks, where technological features (rides and 'artificial' experiences...) substitute for conventional beaches or traditional cultural heritage"(Butler 2011). From Scitovsky's perspective, such investment projects are not likely to lead 


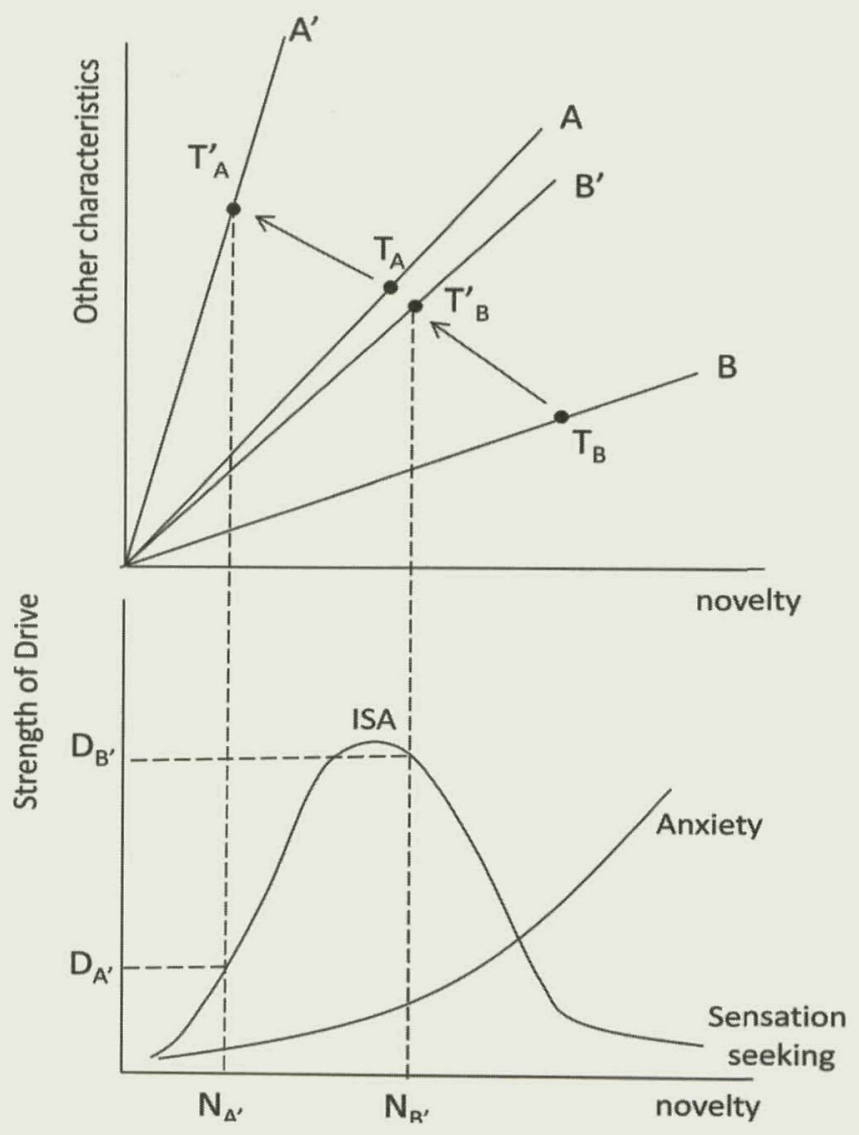

Figure 3 The effect of Habituation among congruent holiday destinations

to a sustained increase in visitors as any competitive advantage created by such new investment is temporary and will quickly be destroyed once even newer types of attractions are built in other destinations. In that sense, the rapid changes observed in the characteristics of resorts can only temporarily compensate for the lack of novelty that is present standardized resort destinations.

This type of dynamic competition for novelty-seeking tourists among tourist destinations resembles a system which features endogenous change (Papatheodorou 2004), and in particular, the process of creative destruction where new innovations incessantly revolutionize the structure from within, thereby destroying the old structure and creating a new one (Schumpeter 1942: 38). An important element of such an evolving system is 'self-transformation' in that new innovations emerge from within the system, and their dissemination throughout the system creates the conditions under which more new innovations can emerge (Witt 2002). In the case of novelty-seeking tourists, the aggregate effect of the habituation process across a large segment of consumers in relation to a tourist destination can create the conditions under which other new destinations can 
successfully emerge supersede existing destinations. If tourists are not habituated to existing sources of novelty at recreational destination, the creation of new novelty at destinations may be premature as existing destinations provide sufficient levels of arousal to tourists. On the other hand, once a tourist segment has become completely habituated to existing attractions, the potential for new destinations to attract demand is relatively greater.

In Figure 3, the consumer has the choice of going on a trip to destination $A\left(T_{A}\right)$ or destination $B\left(T_{B}\right)$ for some duration. After consuming $T_{A}$, the consumer's habituation to $A$ affects their demand for holiday destination $B$. In this case, we assume that the two destinations are congruent, in that the consumer's habituation to $A$ affects the consumer perception of novelty in $B$. Consequently, the effect of habituation is that the mix of characteristics offered by $A$ shifts to $A^{\prime}$ and the mix of characteristics offered by destination $B$ shift to $B^{\prime}$. Hence, whereas prior to the habituation process, $T_{b}$ was perceived as offering too much novelty and therefore eliciting too much anxiety in consumers, the altered perception of novelty due to the consumer's recent travel experienced implies that the consumer would prefer traveling to $T_{B}$, rather than $T_{A}$, since it delivers an amount of arousal that is closer to the ISA, resulting in the consumer possessing a greater drive for destination $B$ relative to destination $A\left(D_{B},>D_{A^{\prime}}\right)$. In this way, the habituation process can theoretically create the condition in which new destinations become more appealing in light of the tourists becoming habituated to existing destinations. As such, this approach allows one to reach a more detailed understanding of when, and to what extent, the existing tourist destination will be subject to periods of crisis in which reorganization and restructuring takes place (Stabler et al. 2010: 9).

In terms of their qualitative nature, the types of novelty that successfully emerge within the system are path-dependent in that their character depends on what type of stimuli consumers have been exposed to in the past. As tourists collectively accumulate greater exposure to specific types of stimuli, one would predict that new stimuli with a similar general character would emerge that would possess a relatively greater amount of arousal potential. This would capitalize on the consumer's familiarity with the concept whilst also differentiating itself by possessing a greater ability to stimulate arousal. In this way, the type of novelty preferred by consumers at any given moment will be the type which balances habituation and arousal potential of stimuli in a way that is dictated by what consumers have experienced in the past. ${ }^{9}$

In light of what is known about the consumer specialization process (see previous section), an alternative strategy to counter slumps in tourist demand may be possible if one recognizes that specialization processes may influence the rate at which consumers become habituated to a particular destination. Rather than focusing on constructing large infrastructure projects and achieving returns to scale, resorts may enact business strategies focusing on fostering specialization processes amongst a particular niche of consumers by which they may potentially increase the number of repeat visits. This involves making a tradeoff between attracting a large number of visitors and instead focusing on a particular segment of consumers whose tastes may be more specifically

9 Take, for example, the emergence of British seaside resorts in the 18th century. A new generation of resorts emerged that were located at the seaside that used sea-water as well as sea-air for medical treatment (Towner 1996: 170). This type of novelty was preceded by the first generation of spa resorts that existed since the 1500 at inland spas that utilized spring water for medical treatment (Towner 1996: 57). 
catered for. These strategies are becoming increasingly popular in a new range of destination that promote eco - and adventure - vacations (Stamboulis/Pantoleon 2003).

To foster consumer specialization, it is important to not only offer goods and services that are characteristically different from existing goods and services, but provide opportunities to consumers to self-modify the products in the "do it yourself" fashion (Pine 1993). Cosgel and Langlois give the example of the Land's End catalogue which, by offering a varied assortment of mix-and-match clothing elements within a coordinated design paradigm, allows consumers to better fine tune a wardrobe to their personal tastes (Langlois/Cosgel 1998: 116). In this way suppliers of goods and services catering to specialized consumer may do well to cater for the specialized consumer's tendency to self-modify aspects of the consumption act. This emphasis on providing flexible learning opportunities to specializing consumers complements the existing observation that there is a growing trend in tourism towards individualistic and specialized forms of holidays (Urry 1990) in which the suppliers focus on a 'post-Fordist' strategy of realizing economies of scope (rather than economies of scale) and offering highly differentiated products (Agarwal 2002).

Finally, it should be noted that fostering specialization and catering to specialized consumers is not without its own challenges. For one thing, there may be a greater need to reorganize institutional structure of markets in order to provide consumers with opportunities to self-modify goods and services (Langlois 2001). An increased focus on customization also has the potential to drive up labor costs as greater care must be taken in maintaining relationships with consumers since producers need to elicit information from consumers about how goods and services should be customized (Gilmore/Pine 1997; Addis/Holbrook 2001). Moreover, customization requires flexible production technologies that are relatively more expensive and time-consuming in nature (Zipkin 2001). Also, among highly specialized consumers, it seems inevitable that consumers have increasingly heterogeneous wants, since differences in the type of knowledge and accumulated tastes become magnified through the specialization process. This could lead to a stage where it is too difficult for suppliers to individually cater for the different likings within a particular niche of specialized consumers.

\section{Conclusion}

This paper has reviewed Scitovsky's theory of recreational consumption in which demand for novel stimuli is motivated by the want for arousal. His work provides a solid behavioral foundation for understanding how recreational demand has grown over time and why new forms of entertainment periodically emerge. However, his theoretical framework does not have an adequate conception of how consumers accumulate subjective consumption knowledge. This has led us to challenge his argument that more convenient forms of entertainment negatively impact the level of consumption knowledge that is possessed by consumers. As an alternative, we blend his approach to novelty demand with Witt's theory of consumer specialization (Witt 2001). This alternative approach delivers better insights into not only how certain new means of entertainment may foster - rather than inhibit - consumer specialization and may also influence the habituation process.

In a way, the theoretical results of this study present an interesting paradox. Via specialization, consumers are stimulated to change and modify the manner in which they gain exposure to arousing stimuli, which strongly affects what goods and services they use. 
On the other hand, because it can inhibit and delay the rate at which consumers become habituated to arousing stimuli, specialization can also dampen the extent to which habituation necessitates change in entertainment-related consumption activities. From a broad historical perspective, this suggests that while consumption activities related to the want for arousal still undergo periodic changes, the underlying sources that drive this change have significantly shifted from those that are related to habituation towards those that are related to consumer specialization. Consumers today have a wide variety of arousing stimuli at their disposal in the form of books, television programs, music, theatre, films and so on. At the same time, when one recognizes that these modern means of entertainment not only deliver arousing stimuli but also provide information which can stimulate insightful learning and specialization, then it becomes clear how such technological progress has significantly increased the opportunities for consumers to accumulate knowledge about consumption activities, gain exposure to new forms of arousing stimuli and share them with their peers. We argue that the resulting specialization process may slow down the rate at which consumers become habituated to arousing stimuli. At the same time, it may accelerate the rate at which they become dissatisfied with services that are not suited to their specialized tastes. Hence modern consumers, rather than abandoning recreation destinations or certain goods and services because they find them no longer arousing, are more likely to alter consumption patterns due to rising mismatch costs.

Finally, the historical emergence of cheap, mass-produced forms of entertainment appears to have increased the extent to which consumer learning patterns are synchronized across the population of consumers. While synchronous changes in consumer behavior tend to be labeled merely a 'fashion' and are attributed to status concerns, such explanations miss a far more important change in the manner in which consumers learn and specialize, namely how consumers learn to satisfy their wants has been universally affected by the emergence of new ISCTs. This misattribution can lead to misleading conclusions being drawn about why consumers' behavior occurred in such a synchronized manner. In the particular context of tourism, this has important implications for understanding why certain destinations become increasingly or decreasingly popular in a coordinated manner, as we have seen in the discussion of the 'Destination Life Cycle' phenomenon.

\section{References}

Addis, M., M. B. Holbrook (2001), On the Conceptual Link Between Mass Customization and Experiential Consumption: An Explosion of Subjectivity. Journalof Consumer Behavior 1: 50-66.

Agarwal, S. (1997), The Resort Cycle and Seaside Tourism: An Assessment of its Applicability and Validity. Tourism Management 18: 65-73.

Agarwal, S. (2002), Restructuring Seaside Tourism. Annals of Tourism Research 29: 25-55.

Amabile, T. (1996), Creativity in Context: Update to the Social Psychology of Creativity. Westview Press, Colorado.

Anderson, J. (2000), Learning and Memory. John Wiley \& Sons Inc, New York.

Bandura, A. (1986), Social Foundations of Thought and Action - A Social Cognitive Theory. Prentice Hall, Englewood Cliffs.

Becker, G.S. (1996), Accounting For Tastes. Harvard University Press, Cambridge, MA.

Berlyne, D. (1960), Conflict, Arousal and Curiosity. McGraw-Hill, USA.

Berlyne, D. (1971), Aesthetics and Psychobiology. Meredith Corporation, New York. 
Beutel M., E. Brähler, H. Glaesmer, D. Kuss, K. Wölfling, W. Müller (2011), Regular and Problematic Leisure-time Internet use in the Community: Results from a German Populationbased Survey. Cyberpsychol, Behav, and SocNetw 14: 291-296.

Bianchi, M. (1998), Taste for Novelty and Novel Tastes. Pp. 64-86 in: M. Bianchi (ed.), The Active Consumer: Novelty and Surprise in Consumer Choice. Routledge, London.

Bianchi, M. (2002), Novelty, Preferences and Fashion: When new Goods are unsettling. Journal of Economic Behavior and Organization 47: 1-18.

Bianchi, M. (2003), A Questioning Economist: TiborScitovsky's Attempt to bring Joy into Economics. Journal of Economic Psychology 24: 391-407.

Braudel, F. (1992), Civilization \& Capitalism $15^{\text {th }}-18^{\text {th }}$ Century: The Structure of Everyday Life. University of California Press, Los Angeles.

Bresnahan, T., A. Gambardella (1998), The Division of Inventive Labor and the Extent of the Market. Pp. 253-282 in: E. Helpman (ed.), General Purpose Technologies and Economic Growth. MIT Press, Cambridge, M. A.

Bryan, H. (2000), Recreation Specialization Revisited. Journal of Leisure Research 32: 18-21.

Butler, R. W. (1980), The Concept of a Tourist Area Cycle of Evolution: Implications for Management of Resources. Canadian Geographer 24: 5-12.

Butler, R. W. (2011), Tourism Area Life Cycle. Goodfellow Publishers, Oxford.

Buzard, J. (1993), The Beaten Track - European Tourism, Literature and the Ways to Culture, 1800-1918. Oxford: Clarendon Press.

Chai, A. (2011), Consumer specialization and the Romantic transformation of the British Grand Tour of Europe. Journal of Bioeconomics 13: 181-203.

Chai, A. (2007), Beyond the Shadows of Utility: An Evolutionary Consumer Theory and and the Rise of Modern Tourism. PhD dissertation. Max Planck Institute of Economics, Jena, Germany.

Chai, A., P. Earl, J. Potts (2007), Fashion, Growth and Welfare: An Evolutionary Approach. Advances in Austrian Economics 10: 187-207.

Chipman, B.D., L. A. Helfrich (1988), Recreational Specialization and Motivations of Virginia River Anglers. North American Journal of Fisheries Management 8: 390-398.

Clancy, M. (1998), Commodity Chains, Services and Development: Theory and Preliminary Evidence from the Tourism Industry. Review of International Political Economy 5: 122-148.

Earl, P. (1998), Consumer Goals as Journeys into the Unknown. Pp. 122-140 in: M. Bianchi (ed.), The Active Consumer: Novelty and Surprise in Consumer Choice. Routledge, London.

Earl, P. E., J. Potts (2000), Latent Demand and the Browsing Shopper. Managerial and Decision Economics 21: 111-22.

Elster, J. (1997), More Than Enough. University of Chicago Law Review 64: 749-764.

Espinet, J. M., M. Saez, G.Coenders, M. Fluvià (2003), Effect on Prices of the Attributes of Holiday Hotels: A Hedonic Prices Approach. Tourism Economics 9: 165-177.

Flinn, M.V. (1997), Culture and the Evolution of Social Learning.Evolution and Human Behavior 18: 23-67.

Foxall, G. R. (1990), Consumer Psychology in Behavioral Perspective. Routledge, London.

Galbraith, J.K. (1958), The Affluent Society. Hamish Hamilton, London.

Getz, D. (1992), Tourism Planning and Destination Life Cycle. Annals of Tourism Research 19: 752-770.

Gilbert, D., J. Abdullah (2004), Holiday Taking and the Sense of Well-Being. Annals of Tourism Research 31: 103-121.

Gilmore, J.H., B. J. Pine (1997), The Four Faces of Mass Customization. Harvard Business Review 75: 91-101.

Goodwin, P. B. (1996), Empirical Evidence on Induced Traffic: A review and synthesis. Transportation 23: 34-45.

Helm, R., S.Landschultze (2009), Optimal Stimulation Level Theory, Exploratory Consumer Behavior and Product Adoption: An Analysis of Underlying Structures Across Product Categories. Review of Managerial Science 3: 41-7.

Hergenhahn, B. R., M. Olson (1997), An Introduction to Theories of Learning. Prentice Hall, New Jersey. 
Inglis, F. (2000), The History of Holidays. Routledge, London.

Kerstetter, D.L., J. Confer, A. Graefe (2001), An Exploration of the Specialization Concept within the Context of Heritage Tourism. Journal of Travel Research 39: 267-274.

Kuentzel, W.F., T.A. Heberlein (1992), Does Specialization affect Behavioral Choices and Quality Judgments among Hunters? Leisure Sciences 14: 211-226.

Lancaster, K. (1966), Change and Innovation in the Technology of Consumption.American Economic Review 56: 14-23.

Langlois, R. N. (2001), Knowledge, Consumption and Endogenous Growth. Journal of Evolutionary Economics 11: 77-93.

Langlois, R. N., M. Cosgel (1998), The Organization of Consumption. Pp. 107-121 in: M. Bianchi (ed.), The Active Consumer. Routledge, London.

Lebergott, S. (1993), Pursuing Happiness - American Consumers in the Twentieth Century. Princeton University Press, Princeton.

Lemelin, R.H., D. Fennell, B. Smale (2008), Polar Bear Viewers as Deep Ecotourists: How Specialisedare they? Journal of Sustainable Tourism 16: 42-62.

Lindner, S. (1970), The Harried Leisure Class. Columbia University Press, New York.

McFarlane, B.L. (1994), Specialization and Motivations of Birdwatchers. Wildlife Society Bulletin 22: 361-70.

McSweeney, F. K., J.M. Roll (1998), Do Animals Satiate or Habituate to Repeatedly Presented Reinforcers? Psychonomic Bulletin \& Review 5: 428-442.

McSweeney, F. K., S. Swindell (1999), General - process theories of motivation revisted: the role of habituation. Psychological Bulletin 125: 437-457.

Mokhtarian, P., I. Saloman (2001), How derived is the Demand for Travel? Some Conceptual and Measurement Considerations. Transportation Research 35: 695-719.

Moreau, C., D. Lehmann, A. B. Markman (2001), Entrenched Knowledge Structure and Consumer Response to New Products. Journal of Marketing Research 38: 14-16.

Niinenan, O., M. Riley (2003), Towards the Conceptualization of Tourism Destination Loyalty. Tourism Analysis 8: 243-246.

Papatheodorou, A. (2004), Exploring the Evolution of Tourism Resorts. Annals of Tourism Research 1: 237.

Parrinello, G. L. (1993), Motivation and Anticipation in Post-Industrial Tourism. Annals of Tourism Research 20: 233-249.

Pine II, B. J. (1993), Mass Customization: The New Frontier in Business Competition. Harvard Business School, Boston.

Priestly, G., L. Mundet (1998), The Post Stagnation Phase of The Resort Cycle. Annals of Tourism Research 25: 85-111.

Richard, M.O., J. C. Chebat, Z. Yang, S. Putrevu (2010), A Proposed Model of Online Consumer Behavior: Assessing the role of Gender. Advances in Internet Consumer Behavior \& Marketing Strategy 63: 926-934.

Russell, R.,B. Faulkner (1998), Reliving the Destination Life Cycle in Coolangatta. Pp. 97-116 in: E. Laws, W. Faulkner, G. Moscardo (eds.), Embracing and Managing Change in Tourism: International Case Studies. Routledge, London.

Sartorius, C. (2003), An Evolutionary Approach to Social Welfare. Routledge, New York.

Saviotti, P. (1996), Technological Evolution, Variety and the Economy. Edward Elgar, Cheltenham.

Schumpeter, J.A. (1942), Capitalism, Socialism and Democracy.Harper and Brothers, New York.

Scitovsky, T. (1976), The Joyless Economy: An Inquiry into Human Satisfaction and Consumer Dissatisfaction. Oxford University Press, Oxford.

Scitovsky, T. (1981), The Desire For Excitement in Modern Society. Kyklos 34: 3-13.

Stabler, M. J., A. Papatheodorou, M. T. Sinclair (2010), The Economics of Tourism. Routledge, London.

Skinner, B.F. (1953), Science and Human Behavior. The Free Press, New York.

Stagl, J. (1995), A History of Curiosity. The Theory of Travel 1550-1800. Harwood, Switzerland. 
Stamboulis, Y., P. Skayannis (2003), Innovation Strategies and Technology for Experience-based Tourism. Tourism Management 24: 35-43.

Steenkamp, J. B., S. M. Burgess (2002), Optimum Stimulation Level and Exploratory Consumer Behavior in an Emerging Consumer Market. International Journal of Research in Marketing 19: 131-150.

Steenkamp, J.B, H. Baumgartner, E. van der Wulp (1996), The Relationships among Arousal Potential, Arousal and Stimulus Evaluation, and the moderating Role of Need for Stimulation. International Journal of Marketing 13: 319-329.

Thompson, R.F., W.A. Spencer (1966), Habituation: A Model Phenomenon for the study of Neuronal Substrates of behavior. Psychological Review 73: 16-43.

Towner, J. (1996), An Historical Geography of Recreation and Tourism in the Western World 1514-1940. John Wiley \& Sons, West Sussex.

Tussyadiah, I.P., D. R. Fesenmaier (2009), Mediating Tourist Experiences: Access to Places via Shared Videos. Annals of Tourism Research 36: 24-40.

Urry, J. (1990), The Tourist Gaze: Leisure and Travel in Contemporary Societies. Sage Publications, London.

Urry, J. (1995), Consuming Places. Routledge, London.

Virden, R. J., R. Schreyer (1988), Recreation specialization as an Indicator of Environmental Preference. Environment and Behavior 20: 721-739.

Vogel, H. (1998), Entertainment Industry Economics. Cambridge University Press, Cambridge.

Wathieu, L. (2004), Consumer Habituation. Management Science 50: 587-596.

Weatherill, L. (1988), Consumer Behavior and Material Culture, 1660-1760. Routledge, London.

Wilson, T., R.M.Y. Suraya (2004), The Tourist Gaze Goes Online: Rojak (hybrid) reception theory. Tourist Studies 4: 69-92.

Windrum, P. (2005), Heterogeneous Preferences and New Innovation Cycles in Mature Industries: The Amateur Camera Industry 1955-1974. Industrial and Corporate Change 14: 10431074.

Witt, U. (2001), Learning to Consume - A Theory of Wants and the Growth of Demand. Pp. 2942 in: U. Witt (ed.), Escaping Satiation.Springer, Berlin.

Witt, U. (2002), How Evolutionary Is Schumpeter's Theory of Economic Development? Industry and Innovation 9: 7-22.

Wordsworth, W. (1844), Kendal and Windermere Railway. Pp. 302-311 in: W. Owen, J. Smyser (eds.), The Prose of William Wordsworth. Oxford University Press, Oxford.

Zajonc, R. B. (1966), Social Facilitation. Science 148: 269-274.

Zipkin, P. (2001), The Limits of Mass Customization. Sloan Management Review 42: 81-87.

Zuckerman, M. (1994), Behavioral Expressions and Biosocial Bases of Sensation Seeking. Cambridge University Press, Cambridge.

Zuckerman, M. (2007), Sensation Seeking and Risky Behavior. American Psychological Association, Washington DC.

Dr. Andreas Chai, Economics, AFE, Griffith Business School, Gold Coast Campus, Griffith University, Qld, 4222, Australia.

a.chai@griffith.edu.au 
Copyright of Jahrbücher für Nationalökonomie \& Statistik is the property of Lucius \& Lucius Verlagsgesellschaft $\mathrm{mbH}$ and its content may not be copied or emailed to multiple sites or posted to a listserv without the copyright holder's express written permission. However, users may print, download, or email articles for individual use. 